\section{IMPROVEMENTS IN BIOMARKERS OF INFLAMMATION AND HEALTH AFTER AN EMPLOYER-MOTIVATED LEISURE TIME PHYSICAL ACTIVITY PROGRAM: A 15- MONTH FOLLOW-UP STUDY}

\begin{abstract}
${ }^{1}$ Marit Skogstad, ${ }^{2}$ Lars-Kristian Lunde, ${ }^{1}$ Bente Ulvestad, ${ }^{3}$ Hans Christian Aass, ${ }^{4}$ Elin Einarsdottir, ${ }^{3}$ Reidun Øvstebø, ${ }^{1} J o s e$ Hernán Alfonso, ${ }^{5}$ Thomas Clemm, ${ }^{6}$ Asgeir Mamen, ${ }^{1}$ Øivind Skare. 'Dept Occupational Medicine and Epidemiology, National Institute of Occupational Health, Oslo, Norway; ${ }^{2}$ Dept for Work Psychology and Physiology, National Institute of Occupational Health, Oslo, Norway; ${ }^{3}$ The blood cell research group, Department of Medical Biochemistry, Oslo University Hospital, Ullevaal, Norway; ${ }^{4}$ Dept of Chemical and Biological Work Environment, National Institute of Occupational Health, Oslo, Norway; ${ }^{5}$ Occupational Health Service department, Mesta AS, Rådal, Norway; ${ }^{6}$ Kristiania University College, Norwegian School of Health Sciences, Oslo, Norway
\end{abstract}

\subsection{6/oemed-2018-ICOHabstracts.463}

Background Manual workers are physically active during work-shift, but they run a higher risk of cardiovascular disease compared to higher educated office workers. Whilst manual workers with regular physical activity during leisure time may have a lower risk, the long-term effects of employer-motivated physical activity during leisure time have not been extensively evaluated.

We aimed to evaluate health effects of employer motivated leisure physical activity (PA) one year after a PA-program, and to study differences between high and low educated participants.

Methods We examined 121 employees in road maintenance before and after an 8 week PA-program. After 15 months, we reexamined 98 participants. We divided self-reported PA-levels into;

- physical activity $\leq 1$ time per week,

- 2-3 times per week and

- $\geq 4$ times a week and registered high and moderate intensity activity after a 15 month follow-up.

We obtained blood pressure, resting heart rate (RHR), blood samples (lipids, glycosylated haemoglobin (HbA1c), Creactive protein (CRP) and selected biomarkers), and applied mixed models to evaluate associations between PA and health parameters.

Results The PA-program yielded favourable health outcomes. Not all were sustainable at the 15 month follow-up. Physical activity was back to baseline values. The diastolic blood pressure increased among men during the 15 month follow-up. Favourable effects on lipids were only maintainable among those who were regularly physical active. Compared to baseline, HbA1c, CRP (log) and interleukin-6 (IL-6) were reduced significantly at the 15 month follow-up of $0.06 \mathrm{mmol} / \mathrm{L}$ (95\% CI: -0.11 to -0.01$), 0.25 \mathrm{mg} / \mathrm{L} \quad(95 \% \mathrm{CI}:-0.46$ to -0.04 ) and $0.39 \mathrm{pg} / \mathrm{mL}(95 \% \mathrm{CI}:-0.75$ to -0.04$)$. Inflammatory markers such as CRP, IL- 6 and TNF- $\alpha$ decreased among the low educated men during follow-up.

Conclusion We found a reduction of HbA1c, CRP and IL-6, mostly pronounced among individuals who remained physically active throughout the 15 months, one year after termination of the PA- program motivated by employer. Manual workers benefit from workplace PA-programs.

\section{4 THE DEVELOPMENT OF COST-EFFECTIVE HEALTH GUIDANCE COURSES FOR MALE WORKERS WITH THE RISK OF METABOLIC SYNDROME}

${ }^{1,2} \mathrm{M}$ Arakida*, ${ }^{1} \mathrm{Y}$ Matsuda, ${ }^{3} \mathrm{M}$ Negishi, ${ }^{2} \mathrm{M}$ Aoyagi, ${ }^{2} \mathrm{E}$ Furuhata, ${ }^{4} \mathrm{~K}$ Otani, ${ }^{5} \mathrm{E}$ Tomizawa. IInternational University of Health and Welfare Graduate School, Minato-ku Tokyo, Japan; ${ }^{2}$ International University of Health and Welfare, Odawara Kanagawa, Japan; ${ }^{3}$ Fujisawa Taxi Co., LTD., Fujisawa Kanagawa, Japan; ${ }^{4}$ Japanese Red Cross Toyota College of Nursing, Toyota Aichi, Japan; ${ }^{5}$ Sikoku University, Tokushima Tokushima, Japan

\subsection{6/oemed-2018-ICOHabstracts.464}

Introduction The health guidance system that focused on Metabolic Syndrome (MetS) for people over 40 years old was launched in 2008 in Japan. This study aimed to evaluate the health guidance courses and the cost effectiveness of the program.

Methods The three courses of the health guidance program for male workers of an automobile parts manufacturing company (age 19 to 60) having the risk of metabolic syndrome were conducted in May - July 2016, November - January 2016 and January - March 2017. Each course of the health guidance was held for three months in which lectures related to MetS and exercises were taught. In addition, physical measurements were recorded. Health education concerning hypertension and salt intake was held in the third course. The indicators of the effects of the health guidance were taken as the amount of change in weight, blood pressure and the measurement of the abdominal circumference. We conducted this study with the approval of the ethics committee of the university that I belonged to.

Results Nmber of subjects was 199 male workers. The cost of one course was 6900-7550 Japanese Yen/person. While there were no significant differences between the effectiveness of the health guidance courses seasonally (summer/winter) nor the age of the workers, the effects of the health guidance were different from the first and third courses from that of the $2 \mathrm{~d}$ course which was conducted around New Year's and was the worst of the three. The first course that was held in spring was the most effective and had the highest cost effectiveness.

Conclusion Previous research reported that there was seasonal variation in body weight and HbA1c. In addition to the influence of seasonal fluctuation, further analysis involving factors of the subjects' health knowledge and physical activity is necessary.

\section{TOBACCO CESSATION PROGRAM IN NATIONAL ROMANIAN TELEVISION}

${ }^{1}$ Carmen Iliana Busneag*, ${ }^{2}$ Lecturer Alexandru Busneag. ${ }^{1}$ National Romanian Television, Medical Department, Bucharest, Romania; ${ }^{2}$ National Institute of Sports Medicine, Bucharest, Romania

\subsection{6/oemed-2018-ICOHabstracts.465}

Introduction The smoking habit is widespread throughout the world, giving rise to great morbidity and mortality and being the leading cause of preventable diseases. In Romania, the percentage of smokers is $26 \%$ and tobacco consumption was 
responsible for the loss of 42000 lives in 2016. Among the stressful professions that endure a high consumption of cigarettes per day, are the stressful professions related to television work: producers, editors, reporters, picture directors. This paper aims to present the tobacco cessation program developed in National Romanian Television in order to promote the health of its employees and to reduce the number of smoking related illnesses.

Methods We started to achieve the present work in the current legislative context, in which the adoption of the Antismoking Law in 2016, prohibited smoking in the public spaces, so also in the spaces of National Romanian Television. That is why we have structured, since February 1, 2017, a Tobacco Cessation Program, by professional categories, insisting on the VBA (Very Brief Advise) but also on the pharmacological methods of quitting (nicotine replacement therapy, varenicline, bupropion).

Result Smoking cessation results were satisfactory in the group of employees with VBA associated with pharmacological therapy $(27.5 \%$ quit smoking and $25.3 \%$ reduced to more than half the number of cigarettes smoked in one day). The tobacco cessation program will continue, requiring the inclusion of all professional categories involved in television work and will be targeted especially on employees with chronic diseases (COPD, asthma, hypertension, chronic ischaemic heart disease, diabetes).

Discussion Smoking cessation is an essential method of promoting health at work and decreasing the number of chronic illnesses and deaths attributable to smoking. We propose in the future the development of the program and the inclusion of behavioural support for smoking cessation as well as CO monitoring in expired air.

\section{SICK LEAVE BENEFITS BY ENDOCRINE DISEASES: A RETROSPECTIVE EPIDEMIOLOGICAL STUDY}

LFT Priester*, DVS Vitor, RV de Brito, DVS Vitor, LR Ferreira. Centro Universitário das Faculdades Associadas de Ensino, São João da Boa Vista, Brazil

\subsection{6/oemed-2018-ICOHabstracts.466}

Introduction Endocrine Diseases (ED) have a high prevalence around the world. In 2014, the World Health Organisation estimated that many adults will be affected by thoses diseases, worldwide. ED are classified as many different chronic diseases with distinct aetiologies, and they are some of the main causes of disability, which can negatively influence productivity in active workers. In Brazil, those disabled workers with ED diseases can apply for Sick Leave Benefits granted by the Brazilian National Institute of Social Security (BNISS). This Institute is responsible for granting benefits and salaries for work disability.

Methods This was a retrospective cross-sectional study which evaluated 538 workers receiving temporary sick leave benefits from the BNISS caused by ED. The workers were evaluated from June 2014 until July 2016 and submitted to a structured analysis for data collection including: gender, age, affiliation to the BNISS and International Classification of Diseases (ICD-10) of each worker's ED.

Results The workers were $63,5 \%$ female with mean age of 42 years-old, and the most prevalent individuals age ranged from 30 to 49 years old (44\%). The most prevalent diseases were associated with obesity (33\%) with ICD-10 E65 and E66, followed by Diabetes $(23,5 \%)$ with ICD-10 E10, E11 and E14, and thyroid associated diseases (7,8\%) with codes E01, E03, E04, E05, E06, E07. The employed affiliation to BNISS was found in $66,5 \%$ of females, and $50 \%$ of males. Other endocrine diseases were found, as amiloidosis (0,2\%) ICD-10 E85, and other endocrine disturbs (4\%) ICD-10 E88.

Discussion The results showed that obesity and diabetes are important risks factors for functional endocrine injuries, enhancing the harmful effects of overweight and hiperglicemic diet to health and quality of life of workers. These data can help new strategies to enhance obesity and diabetes prevention and health promotion programs for workers.

\section{OCCUPATIONAL HEALTH NURSES WORKING AS WORKSITE HEALTH PROMOTION AGENTS}

${ }^{1}$ Pablo Zarate, 'Diego Cuellar, 'Luis Velazquez, ${ }^{2}$ Leila Cura*. ${ }^{1}$ Pan American Energy, Comodoro Rivadavia, Argentina; ${ }^{2}$ Pan American Energy, Buenos Aires, Argentina

\subsection{6/oemed-2018-ICOHabstracts.467}

Introduction Traditional role in occupational nursing had been for many years to assist occupational physicians and provide primary health care services. Worksite health promotion field requires a different role for occupational nurses. Our team was trained in health coaching and started offering a new service for workers. Workers can have their personal coach for lifestyle risk management. In this poster we selected two experiences to communicate the impact of this kind of recourse for worksite health promotion programs.

Methods In an Company a 1000 employees from the oil and gas industry with 98\% of workers screened for lifestyle risks annually, we define as target of the intervention 2 major risks: Hypertension and weight issues. Two wellness programs were offered: Blood pressure initiative and Wise. Occupational Nurses were the health promotion agents in charge of the program implementation. We measure each risk at the beginning and we measure impart of the intervention. Core intervention were health coaching interactions.

Result Wise program 219 enrolled employees, 182 participating, Initial measures: overweight: $36.3 \%$, obese type 1: $33.0 \%$, obese type $2: 16.5 \%$, obese type $3: 4.9 \%$, healthy weight: $9.3 \%$. Final measures: overweight: $37.9 \%$, obese type $1: 34.6 \%$, obese type 2: $12.6 \%$, obese type 3: 4.9\%, healthy weight: 9.9\%.: $71 \%$. Total weight loss: $484.90 \mathrm{~kg}$. Blood pressure program: 935 enrolled and screened employees, 184 employees didn't knew they had hypertension measurements and of them 98 were diagnosed. Healthy habits modification: $71 \%$.

Conclusion Health coaching is a powerful intervention for healthy habits modification in order to reduce lifestyle related risks. Occupational nurses are a strategic group of health professionals for worksite health promotion programs. All this aspects may contribute to develop new roles for occupational health nurses to contribute to build a healthy culture in the workplace.

\section{COST OF PROVIDING OCCUPATIONAL HEALTH SERVICE FOR INFORMAL WORKERS AT SUB-DISTRICT HEALTH PROMOTING HOSPITAL LEVEL}

${ }^{1}$ Simalak Dithisawatwet* ${ }^{2}$ Songsab Pimchainoi, ${ }^{3}$ Sasithorn Thanapob. ${ }^{1}$ The Office of Disease Prevention and Control 8 Udonthani; ${ }^{2}$ The Office of Disease Prevention and Control 7 Khonkaen; ${ }^{3}$ School of Public Health, Walailak University

10.1136/oemed-2018-ICOHabstracts.468 